\title{
Effect of Electrical Contact Resistance on Performance and Transport Characteristics of Proton Exchange Membrane Fuel Cells
}

\author{
Shian $\mathrm{Li}^{1}$, Rongqiang $\mathrm{Wei}^{1}$, Yuanxin $\mathrm{Qi}^{2}$, Guogang Yang ${ }^{1, *}$, Qiuwan Shen ${ }^{1, *}$ \\ ${ }^{1}$ Marine Engineering College, Dalian Maritime University, Dalian, China; \\ ${ }^{2}$ Department of Energy Sciences, Lund University, Lund, Sweden; \\ *E-mail:yanggg@dlmu.edu.cn and shenqiuwan@dlmu.edu.cn
}

doi: $10.20964 / 2019.12 .46$

Received: 2 August 2019 / Accepted: 25 September 2019 / Published: 29 October 2019

In this study, the effect of electrical contact resistance on cell performance and local transport characteristics of proton exchange membrane fuel cells (PEMFCs) are numerically investigated by using a two-dimensional, non-isothermal and two-phase flow fuel cell model. The conservation equations of species, temperature, charge, liquid water and dissolved water were solved to investigate the transport processes of heat and mass transfer, electron and proton transports, liquid water formation and transport, and water transport through the membrane. The mathematical model was validated against the experimental data reported in the open literature. Results showed that the performance is significantly affected by the electrical contact resistance, especially at low cell voltages. In addition, the temperature, liquid water saturation and solid phase potential distribution profiles are greatly influenced by the existence of electrical contact resistance.

Keywords: PEMFCs, Modeling, Contact resistance, Cell performance, Transport phenomena

\section{$\underline{\text { FULL TEXT }}$}

(C) 2019 The Authors. Published by ESG (www.electrochemsci.org). This article is an open access article distributed under the terms and conditions of the Creative Commons Attribution license (http://creativecommons.org/licenses/by/4.0/). 